\title{
Does your reinforced tube have a Murphy EYE?
}

\author{
Kyong Shil Im, MD, PhD • Hae Jin Lee, MD, PhD • \\ Jae Myeong Lee, MD, PhD
}

Received: 3 May 2016/Revised: 10 May 2016/Accepted: 16 May 2016/Published online: 27 May 2016

(c) Canadian Anesthesiologists' Society 2016

\section{To the Editor,}

Wire reinforcement of an endotracheal tube (ETT) is designed to prevent kinking and bending of the ETT, which cause obstruction and increased airway pressure. Reinforced ETTs are used in several settings, including for some patients in a prone position. ${ }^{1,2}$ These ETTs are extremely flexible, however, so inserting and advancing them without a stylet can be quite difficult. Here, we present a case of a reinforced ETT impinging on the wall of the trachea, making ventilation difficult. We received written consent from the patient to report this event.

An otherwise healthy 59 -yr-old man $(162 \mathrm{~cm}, 68 \mathrm{~kg})$ presented for excision of a mass in his back. He was intubated with a size 7.5 reinforced ETT without a Murphy eye (Safety-flex, Mallinckrodt ${ }^{\mathrm{TM}}$, Covidien ${ }^{\mathrm{TM}}$, Dublin, Ireland), which was fixed at $22 \mathrm{~cm}$ from the lips, and adequately ventilated (i.e., equal breath sounds) with a peak airway pressure $\left(\mathrm{P}_{\text {peak }}\right)$ of $18 \mathrm{~cm} \mathrm{H}_{2} \mathrm{O}$. Shortly after positioning prone, the $\mathrm{P}_{\text {peak }}$ increased to $40 \mathrm{~cm} \mathrm{H}_{2} \mathrm{O}$. After bronchospasm was excluded, a suction catheter inserted

Electronic supplementary material The online version of this article (doi:10.1007/s12630-016-0674-2) contains supplementary material, which is available to authorized users.

K. S. Im, MD, PhD - H. J. Lee, MD, PhD .

J. M. Lee, MD, PhD ( $\square)$

Department of Anesthesiology and Pain Medicine, Uijeongbu St.

Mary's Hospital, College of Medicine, The Catholic University

of Korea, Uijeongbu, Republic of Korea

e-mail: jaemng@catholic.ac.kr into the ETT but could not be advanced. As the operation had not yet begun, he was turned supine, and a bronchoscopic examination revealed that two-thirds or more of the ETT lumen was blocked by the wall of the trachea (Figure A; video, available as electronic supplementary material). The ETT was rotated $180^{\circ}$ (Figure B; video, available as electronic supplementary material), was re-secured, and the patient was again turned to a prone position, this time with a $\mathrm{P}_{\text {peak }}$ of $18 \mathrm{~cm} \mathrm{H}_{2} \mathrm{O}$. Approximately 30 min later, the $\mathrm{P}_{\text {peak }}$ again increased and a repeat bronchoscopic examination showed that the ETT was once again obstructed by the tracheal wall. Despite using bronchoscopy, the ETT could not be rotated, nor did a change in head position affect the $\mathrm{P}_{\text {peak. }}$. The operation was expedited and quickly ended. The patient recovered without further incident.

Complications associated with reinforced ETTs have been previously reported and were related to structural problems (e.g., kinking or wire disruption) or were associated with problems due to re-sterilization. ${ }^{3}$ In our case, the reinforced ETT had a normal structure, but it did not have a Murphy eye. There have been previous reports on the use of ETTs without a Murphy eye, ${ }^{4,5}$ all of which reported problems with the patients' airways. Our patient, however, did not have a problem with his airway. If our ETT had had a Murphy eye, this situation might not have occurred. Indeed, after this incident, we switched to using only reinforced ETTs with Murphy eyes (Mallinckrodt ${ }^{\mathrm{TM}}$ Lo-Contour endotracheal tube; Covidien ${ }^{\mathrm{TM}}$, Dublin, Ireland).

As reinforced ETTs are extremely flexible, it is difficult to alter their directional rotation when necessary. In our patient in the prone position, we tried to advance the ETT, but it was difficult because of its enhanced flexibility. We 

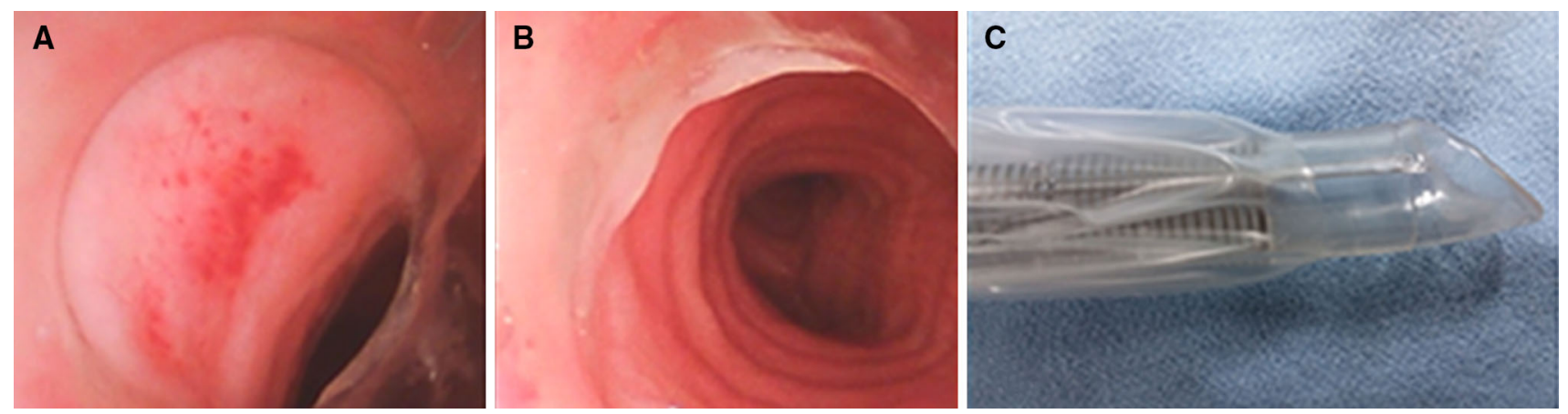

Figure The trachea impinged on more than two-thirds of the endotracheal tube lumen (A). When the tube was rotated, the lumen was secured (B). Reinforced tube without Murphy eye (C).

had had previous problems using reinforced ETTs rather than conventional tubes in other difficult airways.

Reinforced ETTs are used during various operations, including intraoral, facial, and thyroid surgery, and when patients are in a prone position. However, it should be noted that reinforced ETTs are not always superior to conventional tubes for airway management, and the importance of a Murphy eye cannot be underestimated.

\section{Conflicts of interest None declared.}

Editorial responsibility This submission was handled by Dr. Hilary P. Grocott, Editor-in-Chief, Canadian Journal of Anesthesia.

\section{References}

1. Edgcombe H, Carter $K$, Yarrow S. Anaesthesia in the prone position. Br J Anaesth 2008; 100: 165-83.

2. Cassorla L, Lee JW. Patient positioning and associated risks. In: Miller RD, Eriksson LI, Fleisher LA, Wiener-Kronish JP, Cohen WH, Young WL, editors. Miller's Anesthesia. 8th ed. Philadelphia: Elsevier Inc.; 2015. p. 1240-65.

3. Gurumurthy T, Rammurthy K, Mahmood LS, Hegde R. An unusual complication of reinforced tube reuse. J Anaesthesiol Clin Pharmacol 2012; 28: 528-30.

4. Davies $R G$. The importance of a Murphy Eye. Anaesthesia 2001; 56: 915.

5. Thong SY, Teo $Y W$. Unusual cause of airway obstruction associated with the reinforced endotracheal tube in a prone patient. Anaesth Intensive Care 2012; 40: 895-6. 